\title{
La última campaña del general Martínez Campos: Cuba, 1895
}

\section{Luis Navarro García}

Universidad de Sevilla

Al estallar la insurrección de 1895, Martínez Campos fue enviado a Cuba confiando en su capacidad de "pacificador" supuestamente acreditada en El Zanjón. Pero no se le permitió aplicar la ley Abarzuza de autonomía de la isla, recién aprobada, ni se le proporcionaron tropas en cantidad y calidad suficientes. Fracasadas sus tentativas de negociación, después de la victoria de Peralejo, no pudo impedir la progresión de los rebeldes hacia Occidente. En diciembre de 1895, la larga batalla de Las Villas fue el verdadero desastre de España en Cuba.

Toda una línea historiográfica rutinaria, cuando no partidista, ha venido dando a entender que la última guerra hispano-cubana, de 1895 a 1898 , fue una continuada sucesión de fracasos militares españoles que culminaron en el consabido Desastre. Basta, sin embargo, profundizar un poco en las fuentes para advertir que, si bien la contienda comenzó de manera harto desfavorable para los españoles, presenció desde el segundo año una poderosa recuperación de estos, hasta hacer presumible su victoria final en los primeros meses de 1898. ${ }^{1}$ De suerte que si en Cuba hubo un desastre colonial fue en 1895. Desastre hasta hoy mal explicado, y que merecería un más amplio estudio.

La última guerra separatista de la Cuba colonial comenzó, después de fracasar varios intentos, con el alzamiento del 24 de febrero de $1895 .{ }^{2}$

1 Una primera rectificación en este sentido propusimos en Navarro García, Luis: "1898, la incierta victoria de Cuba", Anuario de Estudios Americanos, LV-1, Sevilla, 1998, págs. 165-187.

2 Para una información general sobre este conflicto véase Pérez Guzmán, Francisco: "La Revolución del 95. De los alzamientos a la Campaña de Invasión”, en Barcia, Carmen, y otros: Historia de Cuba. Las luchas por la independencia nacional y las transformaciones estructurales, 1868-1898, La Habana, 1996, págs. 430-546. Alonso Baquer, Miguel: "El ejército español y las operaciones militares en Cuba (1868: La campaña de Martínez Campos)", en De Diego, Emilio (dir.): 1895: La guerra en Cuba y la España de la Restauración, Madrid, 1996, págs. 297-318. Navarro García, Luis: La independencia de Cuba, Madrid, 1992, págs. 349-365; y Las guerras de España en Cuba, Madrid, 1998, págs. 133-194. La celebración del centenario del 98 enriqueció notablemente el pobre panorama de los estudios españoles sobre Cuba que reflejaron los artículos de Amores Carredano, Juan Bosco: "Historiografía española sobre Cuba colonial (1940-1989)" y Domingo Acebrón, M. a Dolores: "Historiografía de las guerras independentistas cubanas. Siglo XIX", ambos en Revista de Indias, n. ${ }^{\circ} 188$, Madrid, 1990, págs. 257-264 y 243-255, respectivamente. De las contribuciones recientes merecen ser destacadas las de Amores Carredano, Juan: Cuba y España, 1868-1898. El final de un sueño, Pamplona, 1998; y De Diego, Emilio: Weyler, de la leyenda a la historia, Madrid, 1998. 


\begin{abstract}
Alzamiento que debía haberse producido simultáneamente en todas o la mayoría de las seis provincias en que estaba dividida la isla, pero que sólo se produjo realmente en la de Santiago de Cuba, y esto en proporciones muy reducidas. El capitán general Emilio Calleja, que estaba sobre aviso y había tomado varias medidas en los días anteriores, dominó fácilmente los brotes que se produjeron en La Habana, Matanzas o Las Villas. Aunque no disponía de muchas tropas - menos de 14.000 hombres en toda la isla; menos de 2.000 en la extensa, accidentada y despoblada provincia de Santiago-, no creyó que el caso fuera alarmante. Envió algunos contingentes por mar a Manzanillo y aseguró que todo quedaría en paz en poco tiempo. La perturbación — se decía en La Habana y en Madrid- se extinguiría por falta de combustible.

Pero esta nueva insurrección produjo desasosiego en España, donde por entonces se ultimaba la aprobación (13 de febrero) y promulgación (12 de marzo) de la ley Abarzuza, que concedía a Cuba y Puerto Rico un considerable grado de descentralización o autonomía, como se venía pidiendo desde hacía medio siglo. Cosa curiosa, algunos grupos de Oriente se habían sublevado al grito de "¡Viva España!” con el programa y la bandera autonomista. Sagasta dispuso el envío de unos miles de soldados a Cuba y aprovechó la primera ocasión para presentar la dimisión, de modo que el gobierno recayera en el partido conservador. Presidido el nuevo gobierno por Antonio Cánovas, en él figuraban el general Azcárraga como ministro de Guerra y D. Tomás Castellano en la cartera de Ultramar. Este cambio acarreó la dimisión del capitán general Calleja y el nombramiento, universalmente aplaudido, de Arsenio Martínez Campos para sucederle. ${ }^{3}$
\end{abstract}

\title{
La personalidad de Martínez Campos
}

En el momento de ser designado en 1895 para el mando en Cuba, Martínez Campos era, como lo dirá poco después el general Weyler, "el mayor prestigio militar de España", razón por la cual no se le debía haber expuesto a un fracaso. A sus sesenta y cuatro años había acumulado una

3 Cánovas encontró a Martínez Campos en el Senado y sin más preámbulo le dijo que había llegado la hora de exigir de su patriotismo que marchase a Cuba para que terminase la insurrección. El general, cogido de sorpresa, manifestó que aunque no le agradaba mucho, estaba dispuesto a ir donde el gobierno le mandase. Reverter Delmas, Emilio: La Guerra de Cuba. Reseña histórica de la insu-

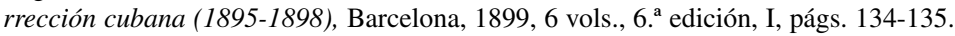


extraordinaria experiencia de la guerra — guerras carlistas, guerras de África, primera guerra de Cuba, guerra cantonal—, así como una reconocida competencia teórica — profesor de la Academia de Estado Mayor-. Había tenido además una destacada actuación política como protagonista del golpe de estado de Sagunto en 1874, alcanzando el grado de capitán general en 1876 y la presidencia del gobierno en 1879 . Entre estas dos fechas había culminado una de sus más destacadas empresas: la pacificación de Cuba mediante el convenio del Zanjón en 1878. "El general, que es en la península el hombre de Sagunto, era para Cuba el hombre del Zanjón". ${ }^{4}$

Nadie dudaba de su bravura. Uno de sus más significados adversarios, el jefe insurrecto cubano Antonio Maceo, le reconocía "pericia militar y arrojo no comunes". ${ }^{5}$ Aunque también se le reconocían otras habilidades, que hacían decir a Pi y Margall que el general Martínez Campos era "tanto o más hábil para el manejo del oro que el de la espada". ${ }^{6}$

Pero no habían de faltarle al general rivales y críticos. Entre estos figuró el coronel Camps y Feliú, que sin ocultar su resentimiento, le consagró todo un capítulo, amén de otras menciones dispersas, en la extensa obra que dedicó a la Guerra de los Diez Años. Allí, negando sus méritos, al tiempo que le llama atolondrado, le atribuye buena estrella: "activo como pocos, posee una naturaleza que nada rinde; no reconoce distancias y en Cuba lo mismo se cuidaba de que le siguieran 200 jinetes que 50. Puede decirse sin exageración que más que el general de un ejército, es un activo explorador de raza árabe que fía todo su porvenir a la fatalidad del destino". Párrafo que podría ilustrar algunos de los episodios que luego han de ocurrir. Dice también de él: "tiene condiciones para ser jefe del E. M. de un buen general, o mandar una división secundando los planes de un general en jefe; pero si se le ha de juzgar como un gran capitán o un insigne gue-

4 Un autonomista: Apuntes sobre la cuestión de Cuba (1897), pág. 98. Los esfuerzos del general por resolver el problema cubano en los días que siguieron al Pacto del Zanjón han sido analizados por Beck, Earl R.: "The Martínez Campos Government of 1879: Spain's Last Chance in Cuba". Hispanic American Historical Review, vol. 56, n. ${ }^{\circ}$ 2, 1976, págs. 268-289.

5 Piedra Martel, Manuel: Memorias. Mis primeros treinta años, La Habana, 1944, pág. 169. "Hombre valiente y audaz" le llama el historiador cubano Casasús, añadiendo: "nos descubrimos ante el valor y la serenidad de Campos". Casasús, Juan E.: La invasión. Sus antecedentes, sus factores, su finalidad, La Habana, 1950, págs. 67-71.

6 Conangla Fontanilles, J.: Cuba y Pi y Margall, La Habana, 1947, pág. 223. Podemos añadir el juicio del conspirador Juan Gualberto Gómez, a quien el general salvó la vida: "España mandó a Cuba a un gran soldado, un habilísimo político, y yo estoy autorizado y tengo hasta el derecho de decir también, un noble corazón: el general Martínez Campos". Gómez, Juan Gualberto: "Discurso en homenaje al mayor general Antonio Maceo", en la recopilación de Emilio Roig de Leuchsenring: Por Cuba libre, La Habana, 1954, 381-392; cita pág. 384. 
rrero, no tiene, no, la talla de un O'Donnell, Espartero y Prim, ni la de otros muchos antiguos y modernos generales, tales como Murillo, Oráa, Córdoba (D. Luis), Moriones y otros que no pasaron de tenientes generales". En la hoja de servicios de Martínez Campos, viene a decir Camps y Feliú, no constan asaltos a plazas de primer orden, ni combates heroicos, ni grandes batallas ganadas, ni retiradas difíciles... “¿En cuántas acciones se ha batido? ¿En cuántas batallas, mandando, ha vencido? ¿En qué momentos supremos, de esos que electrizan a un militar, se ha colocado, sable en mano, a la cabeza de un batallón de cazadores, como Prim en las trincheras de Castillejos, o D. Baldomero Espartero en el puente de Luchana?".? También estas preguntas podrían encontar respuesta en su tercera estancia en Cuba, segunda como capitán general.

Al igual que otros críticos, Camps negaba a Martínez Campos el título de "Pacificador", porque a su juicio el Pacto del Zanjón había impedido una verdadera paz basada en una definitiva victoria militar, que estaba ya al alcance de la mano, y además el Pacto había tenido tan escasa vigencia que inmediatamente después estalló la llamada Guerra Chiquita.

Otro escritor coetáneo, Enrique Piñeyro, cubano revolucionario del círculo de París, escribió acerca del nombramiento de Martínez Campos para el mando de Cuba: "El iluso caudillo aceptó... Estaba él siempre muy cerca de creer que su presencia bastaba para imprimir en todo más favorable aspecto. Dio de esta manera una prueba más de su incapacidad real, de la superficialidad de su memoria y de su espíritu". ${ }^{8}$

Esta apreciación carece, sin embargo, de fundamento. Por el contrario, Martínez Campos, que había defendido la permanencia del capitán general Calleja en Cuba, parecía abatido después de aceptar ese mando. Según el conde de Romanones, cuando el general fue a despedirse de la reina regente, ésta "le vio descorazonado y pesimista: quedó convencida de que no era el hombre para dirigir la guerra". ${ }^{9}$ Y poco después, en la solemne despedida que se le hizo en Madrid, se le oyó murmurar: " $i Q u i e ́ n$ sabe, quién sabe! Lo de ahora no es lo de entonces. Tanto va el cántaro a la fuente...". ${ }^{10}$

7 Camps y Feliú, Francisco de: Españoles e insurrectos. Recuerdos de la Guerra de Cuba, Habana, 1890; (2. ${ }^{\mathrm{a}}$ ed.), págs. 163-177.

8 Piñeyro, Enrique: Cómo acabó la dominación española en América, París, 1908, pág. 93.

9 Romanones, conde de: $D .^{a}$ María Cristina de Habsburgo y Lorena. La discreta regente de España, Madrid, 1947, pág. 99.

10 Ortega Rubio, Juan: Historia de la regencia de D. ${ }^{a}$ M. ${ }^{a}$ Cristina Habsbourg-Lorena, Madrid, 1905, II, pág. 372 . 
A Martínez Campos este nuevo mando le había sido impuesto por Cánovas, que tenía al respecto la misma opinión que Sagasta: Martínez Campos, que tan buen recuerdo debía de haber dejado en Cuba, era el hombre indicado para restablecer la paz en la isla. Además, se pondrían a su disposición inmediatamente todos los medios necesarios para batir a los insurrectos. En cambio, Cánovas, contra el sentir de Sagasta, aplazó la aplicación de la ley Abarzuza para que no pareciese una concesión hecha ante la protesta armada.

\section{Primera fase de la campaña: Peralejos}

El general Martínez Campos llegó el 16 de abril a Guantánamo, y, tal como estaba previsto, desde ese momento comenzó a ejercer el mando, sin previo juramento ni ceremonia. Visitó luego Santiago y otros lugares, para llegar a La Habana el 23 de abril. Casi por los mismos días habían arribado a la isla furtivamente Antonio Maceo, José Martí, Máximo Gómez y otros destacados líderes insurrectos, con lo que la revuelta cobraba una fuerza de la que hasta ahora había carecido.

El mismo 16 de abril había expedido Martínez Campos una orden general en la que daba instrucciones sobre diversos puntos. Una de sus consignas era la de que las columnas no cejasen en la ofensiva: "si por la reunión de partidas rebeldes el número del enemigo no llegara a tres veces más, se le atacará siempre". No había que valorar sólo los sucesos favorables, sino la retirada en orden y disciplina "pues en estas ocasiones es cuando se prueba, no sólo el valor colectivo de la fuerza, sino el mérito del jefe". También disponía el modo de instalar los destacamentos de la tropa, el suministro de quinina y de cartuchos a los soldados y que en el combate sólo se hiciera fuego a la voz del oficial. Sabía que había adversarios más peligrosos que las balas del enemigo: "En esta guerra el mayor número de bajas consiste en la falta de precaución en la comida, en el aseo o en la poca higiene", especialmente obligada en el clima antillano. También ordenaba que no se rematase a los heridos, ni se ofendiese a los prisioneros, y concedía un indulto general por tiempo ilimitado a los rebeldes que se presentasen de paz. ${ }^{11}$

11 Crónicas de la guerra de Cuba. Relación detallada de las operaciones de la campaña, profusamente ilustrada, con interesantes vistas y retratos tomados de fotografías directas, Habana, 1895, págs. 69-76. 
Las operaciones de las semanas siguientes tuvieron un resultado alterno. Maceo sorprendió y rindió el destacamento de Ramón de las Yaguas y Martínez Campos tuvo que confirmar la pena capital dispuesta en consejo de guerra contra el oficial que mandaba el puesto. Con este motivo dirigió a los soldados otra orden general: por primera vez en su vida firmaba una condena por cobardía. Tenía entonces 27.000 soldados a sus órdenes. Después, el 13 de mayo, tuvo lugar la durísima acción del Jobito, donde halló la muerte el teniente coronel Bosch. Pero el 19 de mayo caía José Martí en la escaramuza de Dos Ríos, y se pudo esperar que menguase la fuerza de la insurrección. Sin embargo no fue así.

Por el contrario, siguiendo el plan prefijado, el jefe supremo de las fuerzas mambisas, Máximo Gómez, se dirigió hacia Camagüey, logrando entrar en esta provincia el 5 de junio, cruzando el río Jobabo contra todo pronóstico, en medio de un temporal de lluvias que anuló la vigilancia dispuesta por Martínez Campos. ${ }^{12}$ "Es el primer fracaso de mi vida, pero es de una gravedad inmensa", escribió el capitán general. Y también: "Las esperanzas de evitarlo estaban en el telégrafo, pero éste fue cortado por todas partes y mis órdenes y mis avisos no llegaron, y aquellos escuadrones que yo ansiaba ver llegar y cuyas singladuras contaba como hacen los niños cuando se acercan las vacaciones, llegaron seis días después". ${ }^{13}$

Ya para entonces Martínez Campos, preocupado por el crecimiento de la insurrección, ponderaba "la riqueza que hay que guardar y que por su especialidad, por su diseminación, no se guarda nunca bien y es uno débil en todas partes". No había tropas para impedir que uno tras otro fueran incendiados las haciendas y los ingenios azucareros y el general confesaba haber pecado de optimista. "Siento remordimiento por no haberme atrevido a decir al mes, vengan 50.000 hombres más y vengan en seguida". También empezaba a dudar de la eficacia de su "política de atracción sin debilidad", de buscar la conciliación con los alzados, que rehusaban toda negociación. “¿Es mejor la política de represión, la ley de sospechosos, los fusilamientos en consejo de guerra...? No lo sé, no soy voto; sólo aseguro que esa política no la hago yo, tengo conciencia y sólo el con-

12 Estando cortado el telégrafo, Martínez Campos confió la vigilancia del límite de Camagüey a algunos pastores, pero debido a las lluvias el aviso de estos llegó tarde. Reverter Delmas, Emilio: $\mathrm{La}$ guerra de Cuba..., II, pág. 61.

13 Martínez Campos a Tomás Castellano, 8 julio 1895. En Ortega Rubio, Historia de la regencia..., II, págs. 466-467. 
vencimiento de salvar a mi patria me haría tal vez saltar por encima de mis principios cristianos". ${ }^{14}$

En esta tesitura, viendo en el comienzo de la campaña de Gómez la inevitable ampliación del conflicto, quiso dejar el mando. El 13 de junio telegrafió "que habiendo invadido los insurrectos el Camagüey, cosa que creía imposible y que no había podido evitar, su política y su misión habían fracasado, y por consiguiente ofrecía su dimisión". ${ }^{15}$

Este sería su estado de ánimo cuando se dirigió de nuevo a la provincia de Oriente, y el 12 de julio, contra el parecer del general Lachambre que lo recibió en Manzanillo, salió de esta población para dirigirse a la histórica Bayamo. ${ }^{16}$ Le acompañaban su Estado Mayor y 400 hombres de escolta. Por indicación de Lachambre, comprensiblemente inquieto, se le unieron el general Santocildes y luego, en Veguitas, otros contingentes que venían a componer una columna de 1.150 hombres. Así sumaron 1.550 soldados, de los que 80 eran de caballería. ${ }^{17} \mathrm{Al}$ día siguiente, 13 de julio, reemprendió el camino esta fuerza y, pasado el lugar de Barrancas y cruzado el arroyo Babatuaba, comenzó un tiroteo en las avanzadas. Era la emboscada preparada por Maceo — “el copo", la llamó él—, que se veía ya vencedor del capitán general y conquistador de Bayamo, para lo cual había hecho chapear o despejar una parte del terreno y había abierto trochas transversales al camino por donde pudiera operar su caballería.

De los informes dados por el mismo Martínez Campos y de las otras fuentes, nunca muy precisas, parece desprenderse, sin embargo, que al mismo tiempo fue la vanguardia de Santocildes, que cubría el flanco derecho

14 En cambio, Máximo Gómez promulgaba el $1 .^{\circ}$ de julio un bando prohibiendo, bajo acusación de traición, la introducción de ganado en pie y de cualquier fruto de comercio en las poblaciones ocupadas por el enemigo, así como la realización de la zafra y la labor de las fincas azucareras. Se trataba de paralizar la actividad económica y de sitiar por hambre los poblados españoles. Medida aún más radical, con orden de incendio y destrucción de ingenios, fincas y ferrocarriles, daría ya en Sancti Spiritus el 6 de noviembre. Buznego Rodríguez, Enrique, y otros: Mayor General Máximo Gómez Báez. Sus campañas militares, La Habana, 1986, 2 vols., II, págs. 224 y 42.

15 Ysern, Damián: Del desastre nacional y sus causas, Madrid, 1900, pág. 290.

16 La primera narración de este episodio, elaborada inmediatamente después a partir de informes de testigos e incorporando varios documentos se debe a Gómez Núñez, Severo: La acción de Peralejo, Habana, 1895. Incluye mapa del itinerario de la columna y croquis de la acción. Obsérvese que desde el primer momento el topónimo "Peralejo" aparece tanto en singular como en plural.

17 El general sólo llevaba una pequeña columna de 400 hombres que mandaba el teniente coronel Baquero y en ella iba la guerrilla de Lolo Benítez. Santocildes llevaba unos 400 hombres de los batallones de "Isabel la Católica", más 40 guerrilleros de este mismo cuerpo y otros 40 del capitán Travesí. En Veguitas se les unieron 250 hombres del 6. ${ }^{\circ}$ Peninsular, con el teniente coronel San Martín, y otros 400 de "Isabel la Católica" con el teniente coronel D. Federico Escario y el comandante Díaz de Andino. Había además en Veguitas una sección de ingenieros. Gómez Núñez, La acción..., págs. 7-9. 
de Martínez Campos por un camino aproximadamente paralelo, la que sorprendió a la retaguardia de Maceo, situada en el monte La Caoba. ${ }^{18}$ Después la columna de Santocildes cruzó el terreno que la separaba del capitán general y se situó formando círculo a su alrededor mientras continuaba su marcha hacia Bayamo. Santocildes tomó el mando de toda la fuerza. Vino entonces la parte más dura del combate, con sucesivas cargas de la caballería de Maceo, que la columna rechazó formando cuadros que disparaban en todas direcciones mientras avanzaban, llevando en el centro la impedimenta, el Estado Mayor y los heridos. Así atravesaron la sabana de Peralejos y entraron en un camino limitado por dos cercas de alambre, donde cayó muerto Santocildes que, como todos los generales, jefes y oficiales, se mantenía a caballo. "Eran — dice Gómez Núñez- las dos de la tarde. Nuestros soldados venían marchando desde las 4 de la mañana y combatiendo desde las 10, sin beber ni comer".

Martínez Campos asumió entonces el mando y dispuso el avance de una pequeña fuerza - una sección exploradora y dos compañías- que puso al mando del coronel Máximo Ramos y de sus ayudantes el capitán Miguel Primo de Rivera y su propio hijo Miguel, también teniente, marqués del Baztán. ${ }^{19}$ La acometida a vanguardia a la bayoneta de este contingente hizo retroceder al enemigo, pero la columna se vio encajonada en aquel camino cerrado en ambos lados por fuertes alambradas, y cortado por una barrera que impedía pasar más adelante. En aquel callejón estrecho, parecido a una ratonera, fue tiroteada la columna por los mambises ocultos en el monte cercano. La situación se hacía desesperada cuando Martínez Campos tuvo lo que un cronista llama "una de sus corazonadas": mediante toques de corneta, hizo invertir el orden de marcha, de modo que la retaguardia pasó a ser vanguardia y la que era vanguardia quedó de flanco derecho y de retaguardia. ${ }^{20}$ Toda la fuerza retrocedió hasta alcanzar el punto indicado por el general. Entonces, ante la sorpresa de los enemigos, un tro-

18 Así lo expone un testigo, Piedra Martel, Manuel: Memorias. Mis primeros treinta años, La Habana, 1944, págs. 169-177. Testigos fueron también Miró Argenter, José: Cuba. Crónicas de la guerra. Las campañas de Invasión y de Occidente, 1895-1896, La Habana, 1945, y Boza, Bernabé: Mi diario de la guerra. Desde Baire hasta la intervención americana, Habana, 1924 (1. a ed., 1905), 2 vols. Un testimonio poco utilizado es el del médico de Martínez Campos, Eduardo Semprún, según el cual fue el antiguo cabecilla Ramírez quien avisó de la presencia de Maceo en Bayamo con 7.000 hombres. Guerrero, Rafael: Crónica de la guerra de Cuba (1895), Barcelona, 1895, II, pág. 630.

19 También combatió en Peralejo el otro hijo del general, José.

20 Parte de Martínez Campos. Bayamo, 16 de julio de 1895. Reverter Delmas, La guerra de Cuba..., I, págs. 806-812. Añade el general que entonces pasó el arroyo Babatuaba (sic por Mabay) de a uno y con acémilas y heridos. 
zo de alambrada fue derribado y la columna pudo seguir su marcha hacia Bayamo por un antiguo camino, molestada sólo en la retaguardia por algunos amagos de la caballería mambisa. ${ }^{21}$ Martínez Campos había permanecido al lado de la talanquera o alambrada derribada hasta que pasó la impedimenta y el último herido. Luego, caminando en calma y habiendo recogido el armamento de los muertos, a las nueve de la noche entraba Martínez Campos en Bayamo, su punto de destino.

Es indudable que Maceo no logró su propósito: ni detuvo a la columna española, ni capturó a Martínez Campos, no obstante lo cual uno de los mambises que allí combatieron escribió que "ruidosa fue la victoria alcanzada por los cubanos en Peralejos". ${ }^{22}$ La incomunicación en que momentáneamente quedó Bayamo dio lugar a que corrieran diversos rumores, pero pronto se supo que Maceo había sido rechazado y llovieron las felicitaciones sobre Martínez Campos, aunque alguien le reprochara el peligro en que se había puesto: "su última aventura, de guerrillero más que de general en jefe, ha podido representar para España un desastre terrible". Pero el general había encontrado muy conveniente exponerse: "cuando tenga las fuerzas situadas iré a todas partes con tropa, es decir, iré a los puntos de peligro a dar ejemplo, a animar al soldado, a ver lo que puedo exigir al jefe; fío en mi estrella, y si caigo, ya no me malogro" - concluye, con uno de sus rasgos amargos característicos. En realidad Martínez Campos se había atenido a uno de los preceptos de su orden general: "yo reunía - explica con sencillez- 1.523 hombres y no se suponía que Maceo tuviera más del doble". Luego lo obligado era atacar, aun arriesgando todas las fuerzas del distrito: "no me pareció oportuno retroceder, hubiera perdido la fuerza moral con este valiente ejército a quien tanto exijo, y habría sido un golpe fatal". ${ }^{23}$

21 En una de esas cargas, los mambises quisieron servirse, sin éxito, de una piara de ganado recogido en los potreros cercanos. Las tropas españolas, además de recurrir a la bayoneta, lograron abastecerse de municiones registrando los cadáveres enemigos, que las llevaban con abundancia, del mismo sistema y calibre Remington de las usadas por la columna. Gómez Núñez, pág. 16. Salvador "Lolo" Benítez, capitán de la guerrilla de Guisa, fue a Bayamo durante la acción para traer refuerzos y municiones, no obstante lo cual muchos soldados entraron sin ellas en la población. Guerrero, Crónica de la guerra..., I, págs. 54-61.

22 Miró Argenter, Cuba. Crónicas de la guerra..., págs. 66-82.

23 En otra carta, sin embargo, parece confesar una conducta imprudente: "Yo no sabía ni la fuerza que iba, ni conocía a los jefes que la mandaban; ignoraba que no llevaban repuesto de municiones, ni conocía el sitio (porque antes era bosque y hoy son en gran parte potreros con árboles y cercas de alambre que imposibilitan el paso, y mucho más no llevando tijeras a propósito)".

"Yo no llevaba prácticos, pero quise salir de la situación con un empuje y fue éste tan afortunado que me dio cerca de media hora para enterarme, reconocer el terreno, formar mi plan y distribuir los mandos; sorprendí con mis movimientos al enemigo y reduje el fuego a un solo frente, y eso porque 
Probablemente Maceo había dispuesto de más de 3.000 hombres, aunque desigualmente armados y, lo que es muy importante, con una clara superioridad en caballería, recibiendo importantes refuerzos durante el transcurso del combate, frente a la exigua tropa montada de la columna de Martínez Campos. Este, sin embargo, pudo abrirse paso gracias a su destreza en la maniobra y a la disciplina y potencia de fuego de su infantería. ${ }^{24}$ Fue Maceo quien abandonó el campo. Más aún: en los días siguientes al choque, varias columnas españolas, llamadas por Martínez Campos, acudieron desde Santiago, Holguín y Manzanillo a Bayamo, sin que ninguna de ellas tuviera el menor encuentro con los alzados. El encuentro de Peralejos los había asustado y dispersado.

Una vez regresado a Manzanillo, no obstante, Martínez Campos dio renovadas muestras de aquel pesimismo que lo agobiaba tal vez desde antes de salir de España. Si el 8 de julio vacilaba acerca de la política a seguir y de su capacidad para recurrir a procedimientos más severos, el 25 da a entender a Cánovas que los partidos políticos cubanos no tienen ningún peso en la situación: "poco se puede contar con los tres...; no le queda más recurso a España que sus propias fuerzas". De sus recorridos por la isla, aparte del convencimiento de la inutilidad de los esfuerzos realizados por los autonomistas y por él mismo para pacificar a los rebeldes, ${ }^{25}$ había sacado la impresión de que la masa de la población estaba con los insurrectos.

No quedaba, pues, otro camino que el de seguir un sistema de mayor dureza. Pero "no puedo yo, representante de una nación culta, ser el pri-

creyeron que huía; pero la vanguardia, entonces retaguardia, porque habíamos pasado el camino de Bayamo, los recibió con tal brío... que no sostuvieron el segundo ataque fuerte más de tres cuartos de hora, pues el de persecución de la columna fue de grupos de caballería, que no se atrevió en un sao magnífico de dos leguas a cargar, sino a tirotear detrás de los matojos".

"Como jefe de columna, estoy satisfecho de mí mismo...".

Martínez Campos a Azcárraga. Manzanillo, 24 julio 1895. En Ortega Rubio, Historia de la regencia..., II, págs. 471-472.

24 Frente a lo ocurrido posteriormente en encuentros como el de Mal Tiempo, en Peralejo intervinieron tropas aclimatadas y en cierto modo veteranas (más de la mitad de la columna la componía el regimiento de Isabel la Católica, de guarnición en la isla) y el general contó además con colaboradores tan eficaces como los tres tenientes coroneles - Baquero, San Martín y Escario_ por él tan elogiados, además de los jefes de guerrillas Benítez y Travesí, entre otros.

25 A este fin, aparte el de revistar las fuerzas, se deberían los repetidos viajes realizados a Oriente, de modo que entre abril y septiembre estuvo seis veces en Santiago. En el vapor "Villaverde" recorría las poblaciones costeras —Cienfuegos, Santa Cruz del Sur, Manzanillo, Guantánamo, Baracoa, Nuevitas, etc. - y otras veces visitaba el interior: Puerto Príncipe, Tunas, las poblaciones de Las Villas, Morón, Ciego de Ávila, etc. Sólo a partir de agosto se concentra en el punto de la defensa de Las Villas. Son estos continuos desplazamientos los que dan a su último mando en Cuba un aire de profundo desasosiego paralelo a sus alternativas de optimismo y pesimismo. 
mero que dé el ejemplo de crueldad e intransigencia; debo esperar a que ellos empiecen". "Podría reconcentrar las familias...; aislaría los poblados del campo...". Pero "creo que no tengo las condiciones para el caso. Sólo Weyler las tiene en España...", dice, y con esto está proponiendo el nombre de su sucesor. Aunque de todos modos opina que, después de ganar ésta, "antes de doce años tenemos otra guerra". Esta carta confidencial a Cánovas fue enviada por éste al ministro de Estado, duque de Tetuán, para que la mostrara a la reina regente en San Sebastián. Por su parte el duque prefería no hacer cambios: "Un cambio de sistema en estos momentos podría ser fatal. La guerra sin cuartel nos enajenaría las simpatías en el extranjero". ${ }^{26}$ Parece que Cánovas participaba de esta opinión, y tal vez eso contribuyó a agravar la situación en los meses siguientes.

\section{Segunda etapa: preparando la ofensiva}

Peralejo había sido una ingrata sorpresa para Martínez Campos, que no esperaba un encuentro de tal naturaleza cuando se dedicaba simplemente a revistar guarniciones y distribuir las tropas que le iban llegando, en preparación de una campaña formal que habría de tener lugar en las provincias centrales de la isla, toda vez que Máximo Gómez se iba haciendo dueño de Camagüey y, con la llegada en ese mismo mes de julio de la expedición de Roloff y Serafín Sánchez, volvían a aparecer partidas de rebeldes en Las Villas. En agosto Martínez Campos describía perfectamente el problema: "La insurrección... ya se dominará; pero es preciso paciencia y tiempo, y sobre todo tener comunicaciones rápidas, pues contra lo que es costumbre en esta clase de guerra, hay un núcleo de tres a cuatro mil hombres que no está localizado y que, apoyado en las partidas locales, nos puede dar golpes fatales". ${ }^{27}$ Pero cuando regresó a La Habana se mostraba satisfecho de la situación en que se hallaba Oriente.

En el curso de sus continuos desplazamientos de un extremo a otro de la isla - desasosiego que tal vez revela la falta de subalternos de su confianza-Martínez Campos dedicó varios días a mediados de agosto a organizar,

26 Martínez Campos a Cánovas. Manzanillo, 25 julio 1895; el ministro de Estado a Cánovas. San Sebastián, 20 agosto 1895. En Ortega Rubio, Historia de la regencia..., II, págs. 472-479.

27 Martínez Campos a Tomás Castellano. Entre Manzanillo y Cuba, agosto de 1895. En Ibídem, págs. 476-477. 
desde Santa Clara, ${ }^{28}$ el control y defensa de la provincia de Las Villas, tratando de montar un dispositivo, a semejanza del que existió durante la primera guerra de Cuba, que impidiese a los insurrectos de Oriente y Camagüey tomar contacto con los de esta jurisdicción. Con esto se protegía la parte más poblada y rica de la isla. El elemento fundamental, al menos teóricamente, de ese dispositivo había sido la famosa trocha de Júcaro a Morón, que ahora se hallaba lógicamente abandonada después de haber sido en gran parte demolida para aprovechar sus materiales. Un visitante de estos días dice que en los fuertes que guardaban esa línea había escasa guarnición "y vigilando algunos intervalos, rígidos judas de trapo y cañas, vestidos como soldados, con un fusil sujeto por cuerdas y mirando a la campaña cual si fuesen centinelas". ${ }^{29}$ Poco después los hechos probarían que la trocha no había sido adecuadamente protegida. Martínez Campos dejó en ella muy pocas tropas, tal vez porque no disponía de más, y porque el estado ruinoso de las antiguas defensas impedía su puesta en servicio a corto plazo.

En cambio, antes de realizar su primera visita a la trocha, cuando entre el 8 y 10 de julio recorrió Morón, Ciego de Ávila y Júcaro, ya había previsto una defensa en profundidad con cuatro batallones llegados de la península, formando dos líneas: la primera en los Jatibonicos, para vigilar el territorio comprendido entre estos y la trocha; la segunda en Placetas, Guaracabuya, Báez y Fomento, contando además con caballería y guerrillas para perseguir partidas en el caso de que Máximo Gómez pasase la línea de Júcaro. ${ }^{30}$

Durante su posterior estancia en Santa Clara, Martínez Campos, que pensaba establecer su cuartel general en Placetas, estructuró (15 de agosto) Las Villas, a retaguardia de la trocha, como $5 .^{\circ}$ distrito militar, con los generales Suárez Valdés y Luque como primero y segundo jefe, y dividido

28 Roloff dio un bando obligando a todos los hombres y familias que viviesen cerca de los caminos a concentrarse, amenzando con fusilar a los que se quedasen a menos de una legua de los poblados y fuertes. Esto, dirá Martínez Campos, "da a la guerra un carácter especial y sobre todo determina la concentración en los poblados de una porción de habitantes pacíficos; nos impone la obligación de alimentarlos cuando carezcan de recursos". "Es deber de humanidad y de gobierno, que ya que no pueda por el carácter feroz que el enemigo da a esta guerra y por las costumbres de diseminación de la población rural, evitar los padecimientos de ésta, está en el caso de aminorarlos". Por eso ordena que estas gentes se concentren en poblados con guarnición y en la línea férrea, que se les asignen terrenos para labranzas, y que los ayuntamientos les faciliten recursos. Guerrero: Crónica de la guerra..., II, pág. 173.

29 Un español: Pequeñeces de la guerra de Cuba, Madrid, 1897, págs. 65-70. Una importante contribución sobre las trochas cubanas se debe al general Sequera Martínez, Luis de: Historial de las unidades de Ingenieros en Ultramar (La campaña de 1898), Madrid, 1999, págs. 143-181.

30 Así lo dice en el parte oficial sobre Peralejo. Bayamo, 16 julio 1895. Guerrero, Crónica de la guerra..., I, págs. 62-67. 
en seis zonas, con centro respectivamente en Santa Clara, Remedios, Sagua, Cienfuegos, Trinidad y Sancti Spiritus, adscribiendo a cada zona cierto número de batallones y escuadrones y asignando ( 24 de agosto) a cada una de estas unidades el distrito que debía vigilar. ${ }^{31}$ La fórmula ya era conocida desde la Guerra de los Diez Años y había sido aplicada por el mismo general. Si la trocha y las tropas que debían respaldarla resistían a los rebeldes orientales, Las Villas podrían quedar firmemente en poder de Martínez Campos.

Las tropas que esperaba de España iban siendo enviadas con parsimonia. Hasta abril se habían despachado unos 15.500 hombres. Entre mayo y junio, otros 6.000. Para finales de julio habrían llegado 9.000 más. La primera expedición importante - la sexta, según el cómputo del ministerio de la Guerra-, compuesta por cerca de 25.000 soldados, partió entre el 31 de julio y el 30 de septiembre. Apenas estarían disponibles, recién llegados y sin aclimatar, al producirse el inmediato choque. Peor aún, la mayoría de aquellos contingentes estaban formados por reclutas, carentes casi por completo de instrucción militar, y a los que ahora se les empezaba a dotar de una nueva arma, el fusil máuser, con el que a veces trataban de familiarizarse practicando en la cubierta del barco que los transportaba. ${ }^{32}$ Pero en fin, al llegar octubre contaba, sobre la reducida guarnición existente a principios de año, con unos 55.000 hombres llegados de la península, a los que se sumaban otros 5.000 reclutados en Cuba, más una cantidad similar de guerrilleros y voluntarios movilizados. ${ }^{33}$ El capitán general concentró la mayor parte de esas fuerzas en la provincia de Las Villas. Oriente y Camagüey pasaban a ser, como en la primera guerra, frentes secundarios, donde no dejaban de producirse choques - en el ferrocarril de Puerto Príncipe a Nuevitas, en los convoyes de Tunas o del Cauto- pero donde los españoles se mantendrían generalmente a la defensiva. ${ }^{34}$

31 Reverter, La guerra de Cuba..., II, pág. 439.

32 Reparaz, Gonzalo de: La guerra de Cuba. Estudio militar (Madrid 1896), pág. 101. Para una breve valoración de la calidad de las tropas españolas y sus operaciones véase Navarro García, Luis: "Algunas consideraciones sobre las guerras hispano-cubanas", en Armillas, José A. (ed.): Aragón y la crisis colonial de 1898, Zaragoza, 1998, págs. 121-128.

33 El 18 de septiembre dice Martínez Campos desde La Habana que ya han llegado todos los refuerzos. Cuenta con 80.000 hombres, de los que 63.500 de infantería y sólo 3.900 de caballería. Reverter, La guerra de Cuba..., II, pág. 594.

34 En Camagüey, el jefe insurrecto José María ("Mayía") Rodríguez, siguiendo el ejemplo de Gómez y Roloff, dio plazo de ocho días para que los vecinos se alejasen de la ciudad y los campamentos, bajo pena de muerte, originando un aluvión de refugiados carentes de medios de subsistencia. También prohibió la introducción en la ciudad de leche, carbón, leña, forraje y otros productos del campo. Guerrero, Crónica de la guerra..., II, pág. 320. 
Eso permitió a los rebeldes celebrar en septiembre en Jimaguayú (Camagüey), una asamblea en la que redactaron una Constitución y nombraron un gobierno, y poco después Máximo Gómez desde Camagüey y Antonio Maceo desde Oriente iniciaron la marcha llamada "de invasión" para cruzar la trocha y penetrar hacia Occidente, lo que lograron en 30 de octubre y 24 de noviembre, respectivamente, con sorprendente facilidad.

\section{Tercera fase: de la trocha a Calimete}

Martínez Campos había planeado iniciar operaciones ya bien entrado octubre, suponiendo que para entonces habría concluido la temporada de aguas y los caminos estarían secos. Claramente previó acciones a desarrollar en Sancti Spiritus, Sagua y San Juan de los Remedios (Santa Clara). Pero al mismo tiempo confesaba: "Yo no comprendo qué se propone Gómez", a la vista de la aparente inactividad del dominicano en Camagüey. ${ }^{35}$

El 17 de octubre, sin embargo, comenzó un gran temporal de lluvias que duró hasta fin de noviembre, dificultando seriamente los movimientos y agravando las penalidades de las tropas españolas. ${ }^{36}$ Los huracanes fueron tan fuertes esta temporada que hicieron varar y naufragar al crucero "Colón" en los Bajos de los Colorados (Pinar del Río) y luego al cañonero "Caridad" en la ensenada de Cárdenas. Los destrozos causados por el ciclón se sumaron a los realizados por las partidas rebeldes en plantaciones, ferrocarriles, puentes y telégrafos. Las lluvias hacían inservible el heliógrafo. Estas circunstancias facilitaron la penetración de la fuerza mambisa en el corazón del dispositivo militar español.

Martínez Campos, preocupado al parecer por el estado de la trocha, había recorrido aquellos lugares, y se había arriesgado personalmente una vez más al trasladarse en plena temporada de lluvias y con sólo un pelotón de escolta de Ciego de Ávila a Sancti Spiritus, atravesando territorios por donde se movían las partidas locales. El capitán general decidió suspender las operaciones a finales de octubre. En Las Villas las poblaciones quedaban incomunicadas y se hacía casi imposible coordinar los movimientos de las unidades militares. Así transcurrió el mes de noviembre, durante el cual Máximo Gómez había realizado algunos ataques entre la trocha y el límite de Las Villas, aunque sin pasar el río Zaza que marcaba la divisoria, y sin

35 Reverter, La guerra de Cuba..., II, págs. 701 y 707.

36 Guerrero, Crónica de la guerra..., II, págs. 419-426. 
que pudieran encontrarlo las columnas que lo buscaban. Por entonces, en la última semana de noviembre, partía de España el llamado "tercer cuerpo expedicionario", con 35.000 hombres, que no serían de gran utilidad en las operaciones de diciembre y enero.

El 29 de noviembre se reunían Gómez y Maceo en el potrero Lázaro López, al oeste de la trocha, y allí pronunció Gómez una arenga en la que anunció "la guerra dura y despiadada" — no se trataba ya de la "guerra generosa y breve" de Martí- y el "Ayacucho cubano". ${ }^{37}$ La fuerza expedicionaria era reducida, de unos 4.000 hombres, pero de los que 3.000 eran de caballería. De aquí la movilidad de estas columnas, y de aquí uno de los reproches que se harían a Martínez Campos: el no haber hecho retirar o sacrificar el ganado caballar, lo que permitió a los rebeldes renovar una y otra vez sus cabalgaduras mientras avanzaban hacia La Habana y más allá. Por otra parte, las partidas de Las Villas incursionaban en todas direcciones produciendo el desconcierto entre las columnas españolas.

Después de la conjunción efectuada en Lázaro López, desentendiéndose de su infantería, a la que se le ordenó avanzar hacia poniente por el sur, Gómez y Maceo se lanzaron el 3 de diciembre con la masa de su caballería a cruzar Las Villas con dirección noroeste, apuntando, aunque con constantes quiebros, hacia Colón, Matanzas y La Habana. Los insurrectos habían tomado la iniciativa antes de que el capitán general emprendiera sus operaciones, hasta el punto de que cuando éste salió de La Habana no pudo establecer su cuartel general en Santa Clara, que ya había sido rebasada por los mambises, y hubo de situarse en Cienfuegos. La marcha de los mambises estuvo marcada por sucesivos encuentros en los que la columna insurrecta generalmente eludía el combate que buscaban los pesados batallones de infantería española, previamente disgregados en columnas de quinientos o seiscientos hombres y en destacamentos que debían proteger poblados y haciendas. ${ }^{38}$ El propósito de Martínez Campos había sido ocupar Las Villas para asegurar la zafra. La columna "invasora", en cambio, sólo buscaba progresar, huyendo hacia adelante - por eso se habló de una "ofensiva fugitiva"-, causando el mayor daño posible aplicando la tea a plantaciones e ingenios, con una táctica que no era la del combate, sino la del golpe de mano. Una y otra vez el capitán general disponía los movimientos de las

37 Buznego Rodríguez, Mayor General..., pág. 43.

38 Como dijo el general Salcedo, el ejército había sido distribuido en parte preventiva (protección de ciudadanos, ingenios, cafetales, vegas, ferrocarriles) y parte ejecutiva (las columnas destinadas a cumplir el plan de operaciones). Reverter, La guerra de Cuba..., II, pág. 331. 
columnas por distintos rumbos tratando de cercar a Gómez y Maceo, pero estos invariablemente lograban escapar del cerco dejando a las fuerzas españolas a retaguardia. En el curso de esta marcha tuvo lugar la acción de Mal Tiempo (15 de diciembre), en la que los insurrectos arrollaron con una carga al machete a una bisoña compañía de quintos, que ni conocían el manejo del máuser que portaban, ni fueron capaces de formar el cuadro. ${ }^{39}$

La defensa de Las Villas, en la que se emplearon más de 30.000 hombres - Martínez Campos hizo venir varios batallones de Oriente por mar, hasta Batabanó y La Habana-, había sido rebasada. Martínez Campos, que había tenido su cuartel general en Cienfuegos, se trasladó entonces a Colón, disponiendo una línea defensiva apoyada en el río Hanábana, que también fue burlada: la provincia de Matanzas se había convertido en teatro de batalla, aunque, como de costumbre, la columna insurrecta "culebreaba" - la expresión es del general Arderíus, que informaba desde La Habana - para eludir los choques. Se esperaba contener a los mambises antes de que entrasen en la provincia de La Habana, lo que en principio se logró. Martínez Campos consiguió establecer contacto con el enemigo en el breve y confuso choque de Coliseo ( 23 de diciembre), pero Gómez y Maceo, que de ningún modo deseaban arrostrar un combate regular, consideraron oportuno abandonar el campo y retroceder. ${ }^{40}$ Fue ésta la última ocasión en que Martínez Campos, puesto al frente de una columna, arriesgó su vida en una batalla. Dio la impresión de que se ofrecía como cebo para provocar un choque decisivo con los insurrectos. Combatió como un soldado de fila y declaró luego que sentía que "las llamas salían por delante, por detrás y hasta por los mismos cascos de mi caballo". ${ }^{41}$ Pero los insurrectos

39 "La compañía de Bailén, compuesta de soldados recién venidos, que salían por primera vez a operaciones, al verse sorprendidos de manera tan brusca y en número tan considerable, desconcertáronse, no formaron el cuadro, y como iban desplegados en guerrilla no tuvieron materialmente tiempo de reunirse, siendo víctimas del enemigo. En ese ataque resultaron muertos 60 soldados y heridos 30 . Casi todos de machete". Allí fue visto el coronel Arizón "a caballo bajo el fuego enemigo, dirigiendo a los soldados quintos recién venidos - en el manejo del máuser”. Guerrero, Crónica de la guerra..., II, págs. 446-450. Sobre este combate, además de la obra de Casasús ya citada, véase Castellanos G., Gerardo: Recuerdos épicos. La Invasión. Máximo Gómez. Cruces. Mal Tiempo, La Habana, 1942, y Reyna Cossío, René E.: Estudios histórico-militares sobre la guerra de independencia de Cuba, La Habana, 1954.

40 Llama la atención que un mismo autor cubano, testigo presencial del hecho, hable en un lugar de los "laureles (que) recogeríamos... en la gran función de Coliseo", y algo después reconozca que aquella acción, que duró como un cuarto de hora, fue "una escaramuza... que bajo ningún concepto merece el nombre de acción formal". Pero eso sí, como siempre, "para Martínez Campos fue una derrota completa, decisiva, irreparable", nada menos. Miró Argenter, Cuba. Crónicas de la guerra..., págs. 221 y 228.

41 También dijo entonces: "Si me da una bala se resuelve un problema y se despeja una nebulosa”. Reverter, La guerra de Cuba..., III, pág. 321. Tal vez aludía a su ya insegura situación al frente de la capitanía general. 
eludieron el choque dejando al general ante el espectáculo de los gigantescos incendios que devastaban la riqueza de la provincia de Matanzas..$^{42}$

La batalla de diciembre - la batalla de Las Villas, incluyendo la incursión en territorio de Matanzas hasta Coliseo- había sido, como pronto se vería, la clave de la campaña. En cuatro semanas de continua guerra de movimientos, la red de posiciones y columnas españolas, pese a la abnegación con que las tropas arrostraron todo tipo de penalidades, resultó ser una red con demasiados huecos por los que los jefes insurrectos, disponiendo de expertos guías, y contando en ocasiones con el sabotaje realizado por los empleados de ferrocarriles y telégrafos, habían sabido entrar y salir una y otra vez sin que fuera posible detenerlos y entablar un combate formal. Cuando el mes y el año acabaron, el ejército español de Cuba había sufrido un serio desgaste y su capacidad de acción había quedado muy mermada.

\section{El penoso final y el relevo}

Después de Coliseo, aunque el enemigo había retrocedido, Martínez Campos, tras disponer una concentración de tropas en la línea de Guanábana, Unión de Reyes, hasta la Ciénaga de Zapata, tratando de cubrir la entrada a la provincia de La Habana, se retiró a esta capital desmoralizado. En La Habana fue recibido con aclamaciones en la estación y luego fue objeto el 27 de diciembre de una gran manifestación de apoyo por los tres partidos cubanos ${ }^{43}$ El general se mostró entonces momentáneamente animado, pero ya el 23 había telegrafiado al duque de Tetuán: "Mi fracaso no puede ser mayor. Enemigo me ha roto todas las líneas, columnas quedan atrasadas. Comunicaciones cortadas. No hay fuerzas entre enemigo y La Habana, pues no han llegado a Batabanó los batallones que ordené hace cinco días".

Pero las calamidades no habían concluido aún. Aunque aparentemente rechazados en Coliseo, los mambises no habían sido vencidos. Simplemente, al verse por fin enfrentados a una considerable concentración de tropas españolas, optaron por la retirada. Pero después de haber retrocedido hasta salir de la provincia de Matanzas, volvieron a cruzarla, esta

42 Un destacado estudioso, que considera "inexplicable” que Martínez Campos utilizara infantería para perseguir una fuerza de caballería, encontró muchos "puntos oscuros" que impedían conocer con exactitud lo ocurrido en Coliseo. Reyna Cossío, Estudios histórico-militares..., págs. 37-39.

43 Interesantes datos sobre estos sucesos en párrafos de las "Memorias" inéditas de L. de Goicoechea transcritos por J. L. Franco: Antonio Maceo, págs. 292-296. 
vez por una ruta más meridional, y tras rehusar empeñarse a fondo en el choque con la columna española que les hizo frente en Calimete (29 de diciembre), el 1. ${ }^{\circ}$ de enero de 1896 Gómez y Maceo entraban en la provincia de La Habana. Una vez más las columnas españolas habían quedado atrás. En las semanas siguientes la ágil caballería mambisa recorrió esta provincia en todas direcciones, casi sin encontrar obstáculo, en rápidas marchas nocturnas. ${ }^{44}$ Los pequeños núcleos de población fueron ocupados o asaltados hasta las inmediaciones de la capital, y Maceo emprendió su correría hasta el punto más occidental de la isla, Mantua, en la provincia de Pinar del Río, al que llegó el 22 de enero.

La ciudad de La Habana fue puesta en estado de alerta, temiéndose que pudiera ser asaltada en cualquier momento, mientras que Martínez Campos se esforzaba inútilmente por detener a los insurrectos. Una de sus últimas disposiciones, cuando ya Gómez y Maceo se movían a las puertas de la capital, sería la de situar fuerzas en la línea de Mariel a Artemisa, intentando en vano impedir la penetración de Maceo en Pinar del Río, la provincia más occidental.

A la vista del desconcierto con que se movían las improvisadas columnas españolas, en las que se mezclaban desordenadamente tropas de cualquier unidad y procedencia, toda la prensa pintó entonces con trazos lúgubres el fracaso de Martínez Campos, y en los primeros días de 1896 se hizo patente la desconfianza que hacia él sentían la mayoría de los cubanos leales. Sólo lo apoyaban los autonomistas, pero no los conservadores ni los reformistas. El capitán general telegrafió: "yo no dimito frente al enemigo, no defiendo tampoco el puesto: seguiré en él mientras lo crea el gobierno conveniente".

El 16 de enero de 1896 el gobierno autorizó a Martínez Campos para entregar el mando al teniente general D. Sabas Marín y para regresar a la península. Era, según Pi y Margall, la fórmula eufemística buscada para encubrir una destitución. ${ }^{45}$ De todos modos, Martínez Campos no negaba la realidad y en sus últimas declaraciones en Cuba reconocía: "no ocultaré que he sido poco afortunado en mi campaña, puesto que al llegar yo a $\mathrm{La}$ Habana la insurrección sólo existía en parte del Departamento Oriental y

44 En estos días Máximo Gómez dirigió una carta a Martínez Campos proponiendo que España concediese la independencia a Cuba. “¡No más sangre, General; no más tea! España es y será siempre la responsable de tantos desastres". Miró Argenter, Cuba. Crónicas de la guerra..., págs. 275-276.

45 "Eufemismo de que tal vez no se halle ejemplo en las páginas de la Historia". Conangla Fontanilles, Cuba y Pi y Margall..., pág. 223. 
hoy se extiende por toda la isla...”. ${ }^{46}$ Palabras de las que luego se valió la amarga crítica de Damián Ysern. ${ }^{47}$

Por otra parte, en su despedida de La Habana declaró, sin duda para rechazar algunas críticas de que había sido objeto, que su política no había sido de benevolencia, sino de humanidad y templanza. Pero sin debilidades. "He ordenado el fusilamiento de los cabecillas cogidos con las armas en la mano; he castigado con la pena de muerte a los incendiarios, a los asesinos y a los plateados (bandoleros). Dos cabecillas que fueron detenidos haciendo resistencia a las columnas han sido pasados por las armas. He enviado a Ceuta a las personas sospechosas; he sometido a consejo de guerra a los autores de conjuras contra la seguridad del Estado, a sus cómplices y propagandistas". En cambio a los soldados les dijo: "Mi conciencia me impedía dar a la guerra el carácter que algunos partidos deseaban ver en ella". A los periodistas: "He impedido y me he opuesto a que se repitieran los hechos tristes y luctuosos de la pasada guerra". Y a su sucesor provisional, el general Marín, le advirtió que no se debía combatir a los separatistas con la guerra sin cuartel.

\section{A modo de balance}

En Peralejo y Coliseo desmintió Martínez Campos las acusaciones que le había hecho Camps y Feliú. No era valor personal para luchar al frente de sus tropas lo que le faltaba. Y sin embargo, su última campaña fue un confesado fracaso. Las causas de este fracaso podrían sintetizarse en dos: en primer lugar, Martínez Campos fue probablemente sobrevalorado en 1895 por su papel y sus dotes de pacificador en 1878, sin advertir que el Zanjón sólo fue posible al término de una larguísima guerra que había agotado a los mambises colocándolos en franca inferioridad frente a una metrópoli que entonces recobraba toda su pujanza, y no era ésta la situación en $1895 .{ }^{48}$ En

46 Ortega Rubio, Historia de la regencia..., vol. III, pág. 10.

47 Ysern, Del desastre nacional..., pág. 293, dice: "Encontró la insurrección separatista débil y la dejó potente; la encontró reducida a una provincia y la dejó enseñoreada de casi todas las provincias; la encontró operando en pequeños grupos sin instrucción ni disciplina y la dejó devastándolo todo en grandes núcleos que muchas veces esperaban a pie firme el ataque de las tropas, lo resistían, y en algunos casos atacaban con decisión la misma columna que mandaba el general en jefe". Recoge luego la opinión de que Martínez Campos pudo vencer "si hubiera batallado en vez de negociar, si no hubiese olvidado que unos mismos procedimientos no sirven para todos los casos".

48 Reparaz, por el contrario, dice: "La segunda guerra nos ha sorprendido aún más desprevenidos que la primera, con menos tropas en la isla, mal armadas, mal organizadas, sin caminos estratégicos, sin cuarteles, sin hospitales, sin dinero, sin nada. No habla la Historia de otro caso igual". Reparaz, La guerra de Cuba..., pág. 68. 
segundo lugar, Martínez Campos, fuera cual fuese su capacidad, no dispuso durante su último mando en Cuba de los instrumentos políticos y militares que hubiera necesitado para alcanzar el éxito. El gobierno le negó los medios políticos de conciliación al demorar indefinidamente la aplicación de la ya aprobada ley Abarzuza que podía satisfacer a los cubanos que deseaban alcanzar algún grado de autonomía o descentralización respecto de la península. Más aún, en junio se ordenó la sustitución "gubernativa" de la mitad de los concejales de todos los ayuntamientos, ocasión aprovechada por los gobernadores civiles - contra el parecer de Martínez Campos - para cubrir esos puestos con miembros del Partido Unión Constitucional. Lo mismo ocurrió en las Diputaciones Provinciales en octubre. Con esto, el capitán general perdió el apoyo de muchos reformistas y autonomistas. ${ }^{49}$

El gobierno volcó toda su atención en las medidas estrictamente militares, y logró un éxito en el envío de tropas a Cuba: en enero de 1896, cuando Martínez Campos se sentía desbordado por la incursión de Gómez y Maceo, las tropas regulares en la isla ascendían a 120.000 hombres. Las limitaciones que aquejaban a esta fuerza eran, sin embargo, importantes. Los contingentes fueron llegando con gran lentitud, de modo que durante los primeros meses de su gestión Martínez Campos apenas contaba con tropas. A las deficiencias ya observadas en las anteriores guerras de Cuba - excesiva juventud y pobre condición física de los soldados, especialmente sensible en un medio natural que les era en principio hostil, más la carencia generalizada de instrucción militar y el mal funcionamiento de la administración y la sanidad en el ejército- hay que añadir otros desajustes: la ausencia de un Estado Mayor y, hasta fecha muy tardía, de un cuadro de mandos proporcionado al volumen y grado de dispersión que iba adquiriendo aquel ejército; ${ }^{50}$ la escasa presencia entre las fuerzas españolas de la caballería, que debiera ser la principal arma contra los mambi-

49 Un autonomista, Apuntes sobre la cuestión..., pág. 123. Roldán de Montaud, Inés: La Unión Constitucional y la política colonial de España en Cuba (1868-1898), Madrid, 1991, págs. 664-667. "En esta ocasión las bazas de Martínez Campos se reducían al incremento en el número de soldados y a su talante conciliador... Por añadidura, aun cuando Martínez Campos venía con la idea de lograr una nueva transacción, sus concesiones políticas al autonomismo fueron nulas y en la renovación de ayuntamientos actuó con la orientación clásica de favorecer a los conservadores". Bizcarrondo, Marta, y Antonio Elorza: Cuba/España. El dilema autonomista, 1878-1898, Madrid, 2001, págs. 360-361.

50 Hasta los primeros días de noviembre no llegaron a La Habana los tenientes generales Marín y Pando, designados para mandar los dos cuerpos de ejército de Occidente y Oriente de Cuba. Con ellos llegó todo un plantel de generales de división y de brigada con los que podrían reorganizarse las fuerzas españolas. 
ses; ${ }^{51}$ y la lenta y al mismo tiempo inoportuna introducción del nuevo fusil máuser en las unidades combatientes.

Muchas de estas deficiencias de orden militar serían paliadas o superadas más adelante, lo que contribuiría a cambiar el signo de la guerra en 1896 y 1897, pero para entonces ya no estaba el hombre de Sagunto y del Zanjón al frente del ejército español en Cuba. Se puede, en cambio, atribuir a la conciencia de estas limitaciones el pesimismo que se advierte, desde el primer momento, en Martínez Campos y que aflora sin disimulo cuando, a mediados de junio, al anunciar la entrada de Gómez en Camagüey, consideró que su política y su misión habían fracasado. Poco después se adelantaba a proponer sucesor. Al no serle aceptada esta sugerencia, se vio abocado a adoptar verdaderos planes de guerra, pero lo único que resultó de ellos fue la acción temeraria de Peralejo y el complicado dispositivo de ocupación de Las Villas. Anunció que comenzaría la campaña al terminar las lluvias, pero permitió que fueran Gómez y Maceo quienes tomaran la iniciativa y sembraran el caos en las provincias occidentales. La primera preocupación de su sucesor Weyler al asumir el mando sería la de reorganizar las fuerzas a fin de disponer de un verdadero ejército.

Pero si cabe hablar de deficiencias y errores al tratar de la última campaña de Martínez Campos, también parece justo añadir que, como él mismo dijo, no le acompañó la fortuna en esta ocasión. Ocasión única en que los insurrectos pudieron llevar a cabo la incursión hacia Occidente,, 52 y en la que por otra parte alcanzó la máxima expansión su menguado potencial militar. A partir de enero de 1896 no hicieron sino retroceder, sin poder reponer efectivos y acosados por un ejército expedicionario y unas fuerzas locales cada vez más eficaces. Pero Martínez Campos ya había advertido que no era aquella la guerra que él quisiera mandar.

51 Una prueba del recurso a la improvisación: "Como en Cuba nada había preparado para la guerra, como no fuera el enemigo, la escasa infantería de marina que se envió, en vez de guardar los buques y las costas, hubo que emplearla como infantería del ejército y enseñar a montar en pocos días a unos cuantos oficiales y soldados para que sirvieran de base a la guerrilla de cuerpo, con lo cual llegamos a tener caballería de marina”. Un español, Pequeñeces de la guerra..., pág. 102.

52 "La era de las invasiones a Occidente se había cerrado para siempre. Esta operación militar... no se podía hacer más que una sola vez, y precisamente en la fecha en la cual se realizó, y nunca después, como afirma José Miró. Dos o tres meses más tarde, tal vez hubiera sido imposible, y en ese año 97 jamás; entre mil razones, por una sola: porque llegados por milagro, caídos del cielo cuatro o cinco mil mambises en las provincias de Matanzas y La Habana, para ser aniquilados no tenían los españoles que atacarlos; bastaba dejarlos solos, y en estas desoladas provincias se hubieran muerto fatalmente de hambre, no únicamente ellos, sino hasta sus propios caballos". Souza, Benigno: Máximo Gómez, el Generalísimo, La Habana, 1972 (1. a ed., 1936), pág. 206. 
LUIS NAVARRO GARCÍA

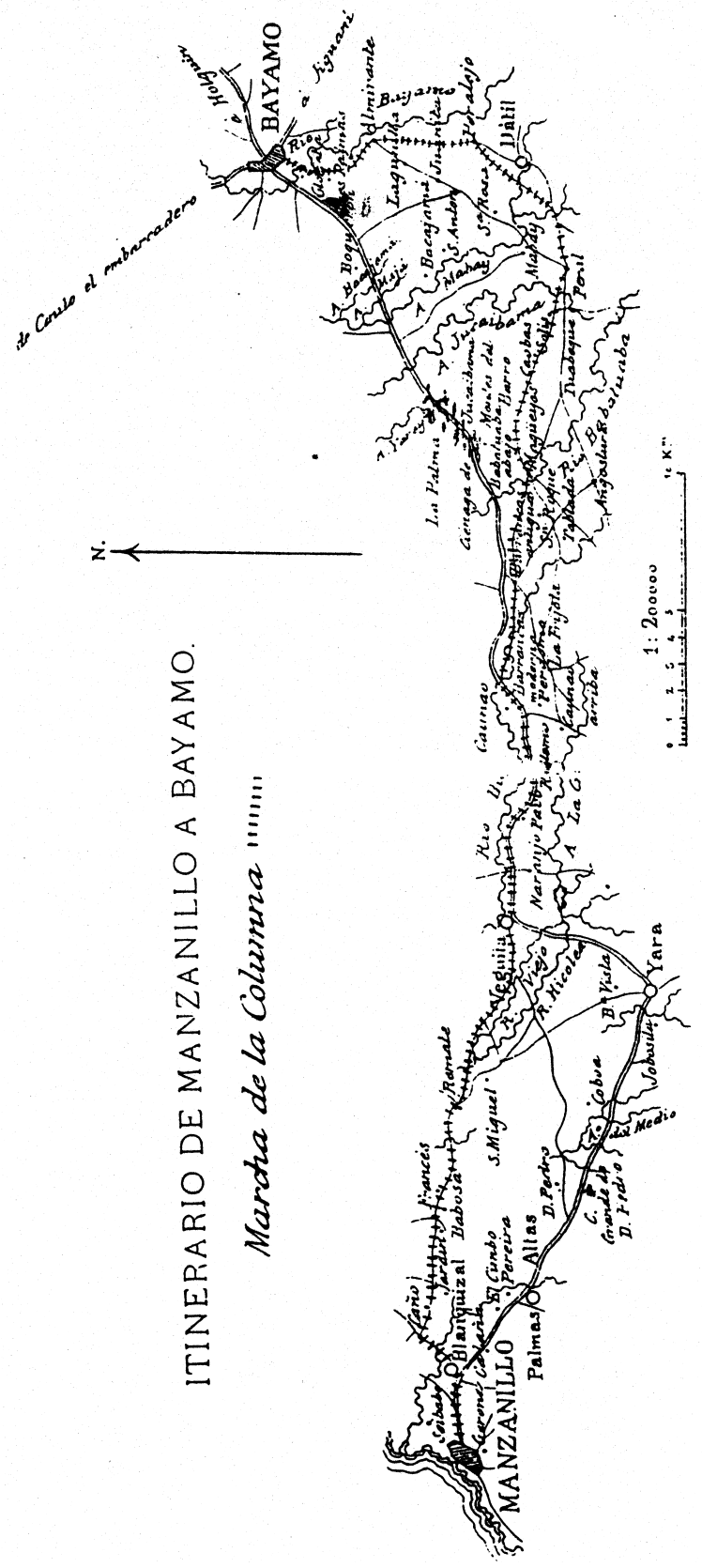

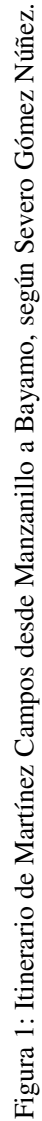


LA ÚLTIMA CAMPAÑA DEL GENERAL MARTÍNEZ CAMPOS: CUBA, 1895

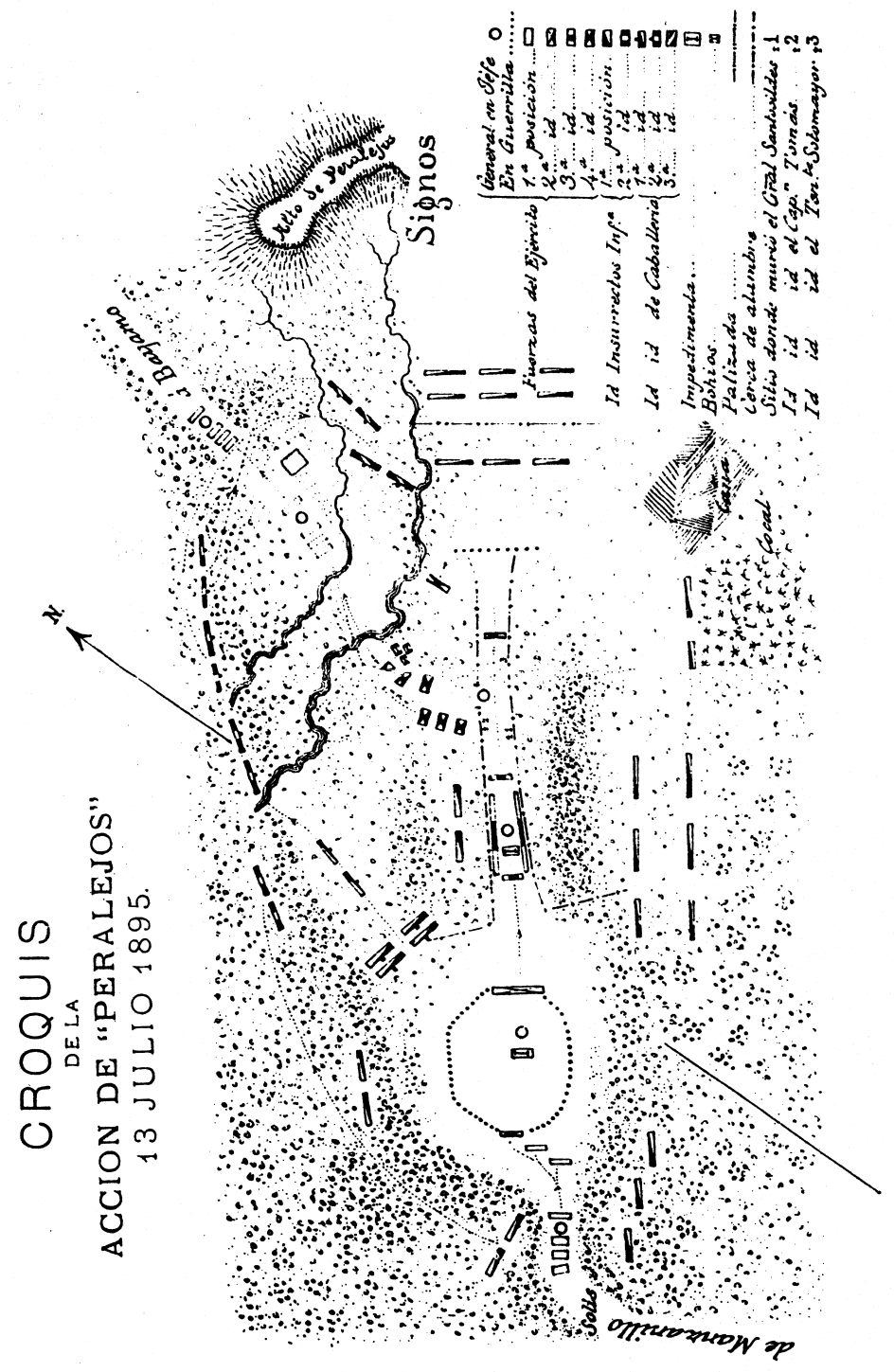




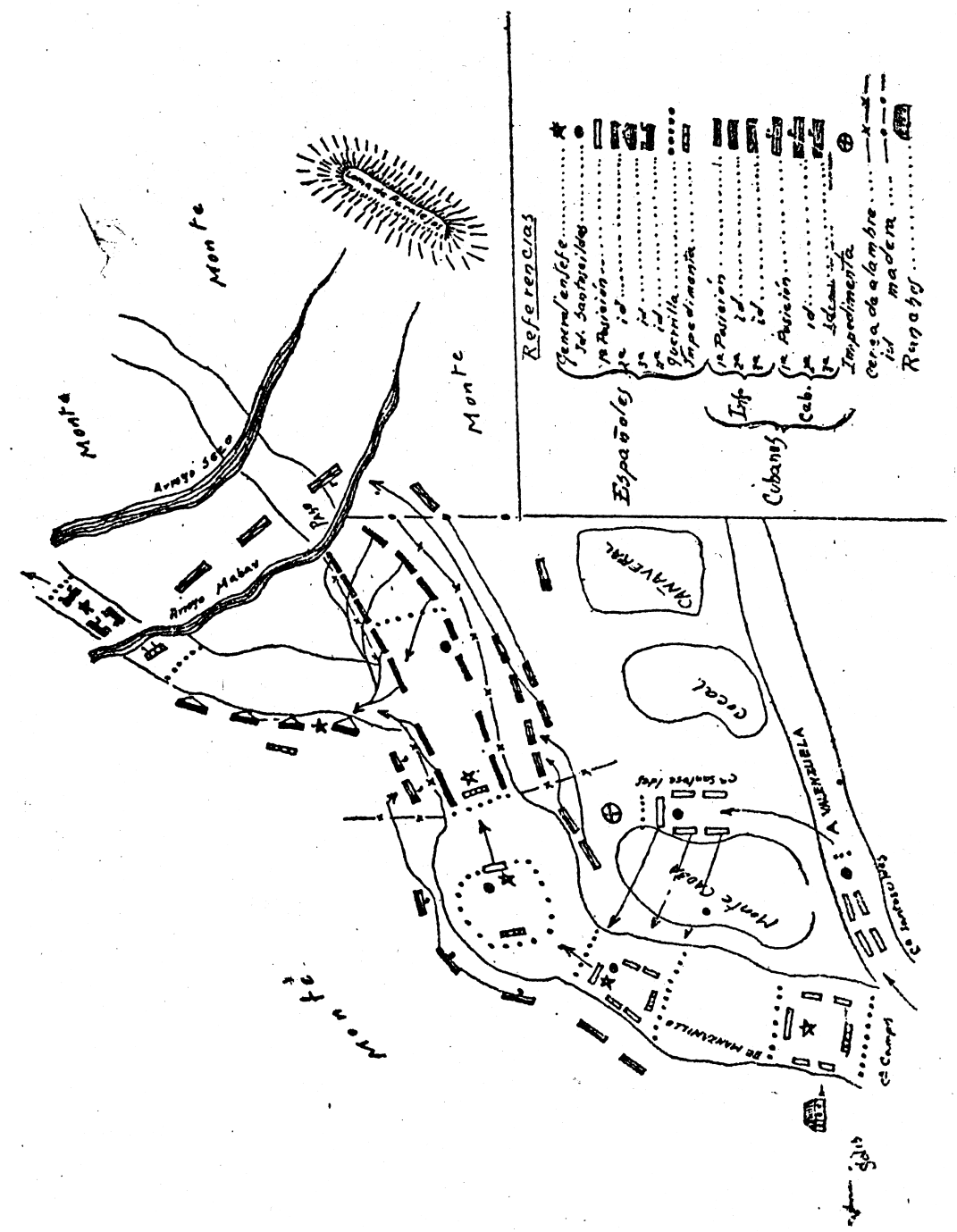

CROQUIS DE LA ACCION DE "PERALEJOS"

Por el General Federico de Monteverde.-13 de Julio 1895.

Reproducción hecha por el ler. Tte. Angel Cremata de un boceto con láplz.

Figura 3: Croquis de Peralejos debido al general Monteverde, reproducido por Casasús. Se advierte el flanqueo inicial de Santocildes, acción del monte Caoba y el episodio de la alambrada. 